\title{
Study and Application of Electrochemical Impedance Spectroscopy for Quickly Evaluating the Performance of Coatings and Predicting the Failure Time in the Development of Waterborne Epoxy Micaceous Iron Oxide Coatings
}

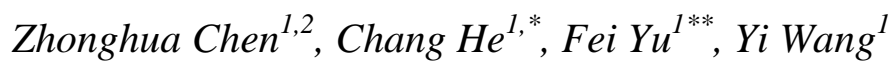 \\ ${ }^{1}$ College of Material Science and Engineering, South China University of Technology, Guangzhou \\ 510640, China \\ ${ }^{2}$ Guangzhou Jointas Chemical Co. Ltd., Guangzhou 510530, China \\ *E-mail: hechscut@163.com \\ ***ail: flyb1999@gmail.com
}

doi: $10.20964 / 2017.04 .64$

Received: 14 January 2017 / Accepted: 3 March 2017 / Published: 12 March 2017

The possibility and necessity of using electrochemical tests to characterize the coating performance and guide the development and application of coating products were discussed. An attempt was made to establish the relationship between the electrochemical parameters and the macroscopic behavior of the coating. Waterborne micaceous iron oxide epoxy coatings were prepared and characterized by SEM, Electrochemical Impedance Spectroscopy (EIS) and conventional corrosion tests. The effects of the particle size and the pigment volume concentration (PVC) on the corrosion properties were discussed. Results revealed that the good anticorrosive performance of the paint was obtained when the 600-mesh-sized MIO was used and the pigment volume concentration (PVC) was 39\%. The consistency of the two EIS parameters (the partial fitting coating resistance $\mathrm{R}_{\text {part }}$ and the phase angle at $10 \mathrm{~Hz}$ ) for evaluating the performance of the coatings was confirmed. The electrochemical failure time (EFT) was defined, and then compared with the macroscopic blistering time, which verified the possibility of applying this parameter in the development of coating products.

Keywords: MIO; EIS; coating performance; rapid evaluation; electrochemistry failure time

\section{$\underline{\text { FULL TEXT }}$}

(C) 2017 The Authors. Published by ESG (www.electrochemsci.org). This article is an open access article distributed under the terms and conditions of the Creative Commons Attribution license (http://creativecommons.org/licenses/by/4.0/). 